(1)

CrossMark

\title{
The new haemodynamic definition of pulmonary hypertension: evidence prevails, finally!
}

\author{
Marius M. Hoeper (1) ${ }^{1}$ and Marc Humbert (1) ${ }^{2,3,4}$ \\ Affiliations: ${ }^{1}$ Dept of Respiratory Medicine, Hannover Medical School and German Center of Lung Research \\ (DZL), Hannover, Germany. ${ }^{2}$ Faculté de Médecine, Univ. Paris-Sud, Université Paris-Saclay, Le Kremlin- \\ Bicêtre, France. ${ }^{3}$ INSERM UMR_S 999, Le Plessis-Robinson, France. ${ }^{4}$ Service de Pneumologie, Hôpital de \\ Bicêtre, Assistance Publique-Hôpitaux de Paris, Le Kremlin-Bicêtre, France.
}

Correspondence: Marius M. Hoeper, Dept of Respiratory Medicine, Hannover Medical School, 30623 Hannover, Germany. E-mail: hoeper.mariusamh-hannover.de

@ERSpublications

The proposal to redefine pulmonary hypertension by lowering the mean pulmonary artery pressure threshold from $25 \mathrm{mmHg}$ to $20 \mathrm{mmHg}$ is supported by strong scientific evidence http://ow.ly/ eajR30nHA2E

Cite this article as: Hoeper MM, Humbert M. The new haemodynamic definition of pulmonary hypertension: evidence prevails, finally!. Eur Respir J 2019; 53: 1900038 [https://doi.org/10.1183/ 13993003.00038-2019].

Since the 1st World Health Organization Symposium on Pulmonary Hypertension, which took place in 1973 in Geneva, Switzerland, every medical student around the world learnt, or at least should have learnt, that pulmonary hypertension $(\mathrm{PH})$ is defined by a mean pulmonary arterial pressure (mPAP) $\geqslant 25 \mathrm{mmHg}$ at rest (in fact, the original cut-off was $>25 \mathrm{mmHg}[1,2]$, but was changed to $\geqslant 25 \mathrm{mmHg}$ during the 4 th World Symposium on Pulmonary Hypertension, held in 2009 in Dana Point, CA, USA [3, 4]).

During the 6th World Symposium on Pulmonary Hypertension, which took place in 2018 in Nice, France, a working group led by G. Simonneau proposed revising the haemodynamic definition of $\mathrm{PH}$ and lowering the threshold from $\geqslant 25 \mathrm{mmHg}$ to $>20 \mathrm{mmHg}$ [5]. To many participants, this proposal came as surprise and critical voices were raised arguing that there is no need to change the $\mathrm{PH}$ definition, that the old definition was the basis of all treatment trials, that we don't know how to treat patients with mPAP between 20 and $24 \mathrm{mmHg}$, and that the new definition may lead to overdiagnosis and overtreatment of $\mathrm{PH}$.

Some of these concerns are reasonable, others not, but we will come back to this later. First, we need to underscore where the $25 \mathrm{mmHg}$ threshold came from [5]. The $1973 \mathrm{WHO}$ conference was held in the aftermath of an epidemic of so-called primary PH in Germany, Austria and Switzerland that was caused by aminorex fumarate, an anorexigen [6]. The conference was focused primary on PH while most other forms of $\mathrm{PH}$ were not addressed in detail. In the proceedings from this meeting, the authors stated that the mean pressure in the pulmonary artery does not normally exceed $15 \mathrm{mmHg}$ when the subject is at rest in a lying position. This value is little affected by age and never exceeds $20 \mathrm{mmHg}$. Hypertension is definitely present if the pressure exceeds $25 \mathrm{mmHg}$ [1]. Hence, the participants of the Geneva conference acknowledged that $20 \mathrm{mmHg}$ is the upper limit of normal, which was later confirmed by KovACs et al. [7] in a systemic review of the available evidence, rigorously showing that normal mPAP is $14.0 \mathrm{mmHg}$ with a standard deviation of $3.3 \mathrm{mmHg}$. Thus, the $25 \mathrm{mmHg}$ threshold was pragmatic, not scientific, in order to 
discriminate rare but severe cases of primary $\mathrm{PH}$ from other more common causes of $\mathrm{PH}$ due to chronic lung or heart diseases, which usually present with much lower mPAP.

We have been aware for many years of the gap between $20 \mathrm{mmHg}$, the upper level of normal, and $25 \mathrm{mmHg}$, our old PH threshold. In Dana Point, we discussed and rejected introducing the term "borderline $\mathrm{PH}$ " for mPAP from 21 to $24 \mathrm{mmHg}$ [8], but the voices calling for a new $\mathrm{PH}$ definition became louder [9]. What has led Simonneau et al. [5] to propose the change now? Well, the evidence that mildly elevated mPAP is associated with morbidity and mortality has simply become too strong to ignore any longer, and consistent data come from pulmonary arterial hypertension (PAH) as well as from other forms of $\mathrm{PH}$.

Accumulating evidence from PAH associated with systemic sclerosis is teaching us that patients with mPAP between 21 and $24 \mathrm{mmHg}$ have symptoms comparable to those who fulfil the classic definition, have an increased risk to progress to $\geqslant 25 \mathrm{mmHg}$ and have a higher mortality than patients with $\mathrm{mPAP}$ $\leqslant 20 \mathrm{mmHg}$ [10-13]. Although these data have been known for several years, there is still no recommendation to treat these patients before their mPAP reaches $25 \mathrm{mmHg}$. For patients with systemic sclerosis, symptoms of PAH and mPAP between 21 and $24 \mathrm{mmHg}$, this created the paradoxical situation that early PAH was evidently present but treatment not "permitted" because of lack of randomised controlled data due to inclusion criteria based on a biased PH definition, while, at the same time, the community was calling for early diagnosis and even introduced screening programmes [14-16]. The new definition will help these patients to receive proper management and will facilitate their inclusion in future clinical trials.

In recent years, early detection programmes have also been offered to patients with heritable PAH with identification of early pulmonary vascular disease relentlessly progressing to severe disease [17, 18]. Similarly, chronic thromboembolic pulmonary hypertension (CTEPH) is another major pre-capillary pulmonary vascular disease where mPAP below $25 \mathrm{mmHg}$ is associated with significant exercise limitation, progressive haemodynamic compromise and poor outcomes [19]. Major improvements after successful desobliteration argue for therapeutic interventions in selected patients with symptomatic pulmonary vascular disease but mPAP $<25 \mathrm{mmHg}[20,21]$.

Perhaps even more importantly, while the PH field has focused for many years on PAH and CTEPH, two relatively rare forms of $\mathrm{PH}$, we came to learn that the largest $\mathrm{PH}$ burden is carried by patients with chronic left heart diseases and chronic lung diseases and that in these conditions, the development of $\mathrm{PH}$ is associated with a 2-3 fold increased mortality risk [22]. Hence, our focus has to broaden and has to include these forms of $\mathrm{PH}$ as well, and for that we need an evidence-based, comprehensive haemodynamic definition.

And the evidence is there, strong and clear. For patients with chronic lung diseases, it has been known for some time that even mildly elevated PH pressures are associated with an increased risk of death [23, 24]. More recently, similar observations have been made in mixed patient populations [25]. In the largest series so far, MARON et al. [26], analysing data of more than 21000 patients from the US veteran's system, found that the hazard ratio of death for patients with mPAP between 19 and $24 \mathrm{mmHg}$ compared to those with a mPAP $<19 \mathrm{mmHg}$ was 1.23 (95\% CI 1.12-1.36; $<<0.001)$. Of note, these patients were not suffering from PAH. These were patients we encounter much more frequently in daily practice, i.e. mostly elderly patients of whom approximately $75 \%$ had left heart disease and about 30\% COPD. The findings of MARON et al. [26] were confirmed by the Vanderbilt group, who analysed data from 4343 patients and found an increased risk of death for patients with mPAP of 19-24 mmHg compared to patients with mPAP $<19 \mathrm{mmHg}$ (HR 1.31, 95\% CI 1.04-1.65; p<0.001) [27].

Taken together, the revised definition is strongly supported by evidence, but does it also come with an increased likelihood of patients being misdiagnosed and mistreated as $\mathrm{PH}$ ? The answer is probably yes and no at the same time. Yes, because some less experienced physicians may misinterpret the new definition and inappropriately treat (more) patients with drugs approved for PAH; and no, because a diagnosis of $\mathrm{PH}$ does not imply a treatment indication per se but requires a sophisticated work-up in expert centres, as strongly recommended in $\mathrm{PH}$ guidelines $[28,29]$. Expert centres should be able to make a correct diagnosis and treatment decision independently of the old or new haemodynamic definition.

No single cut-off value is perfect. Moving it to the right, or in case of $\mathrm{PH}$, leaving it at $25 \mathrm{mmHg}$, lowers the likelihood that patients are wrongly labelled with $\mathrm{PH}$ but increases the likelihood that patients who suffer from $\mathrm{PH}$ (or PAH) have their condition not diagnosed and not treated. The systemic sclerosis example mentioned earlier should teach us a lesson. Opponents may argue that lowering the threshold to $20 \mathrm{mmHg}$ increases the likelihood of over-diagnosing PH, but again, the evidence is incontrovertible that anything above $20 \mathrm{mmHg}$ is not normal and associated with an increased mortality risk. Over-treatment? 
For $\mathrm{PH}$ associated with left heart disease and lung disease, even with the current definition we have no specific $\mathrm{PH}$ treatment $[30,31]$, so the revised definition should not change anything, except for better identifying patients in need of a therapy and helping to include them into future clinical trials. For pre-capillary PH, especially PAH, SimONNEAU et al. [5] reinforced the requirement of a pulmonary vascular resistance $\geqslant 3$ Wood units, which is currently the best criterion for pre-capillary pulmonary vascular disease. Hence, the revised definition will have little effect on how we treat patients with PH today, but it will foster future research that no longer leaves behind a sizeable and important group of patients in need for better treatments.

In summary, there is no debate that the upper limit of normal mPAP is $20 \mathrm{mmHg}$ and that any value above that is abnormal. There is no debate either that this cut-off value does not define a disease per se. An elevated mPAP can have different causes, such as an increased cardiac output, left to right cardiac shunts, elevated pulmonary artery wedge pressure due to left heart disease, increased blood viscosity and, in a minority of cases, a true pre-capillary pulmonary vascular disease. Pre-capillary PH due to pulmonary vascular disease will be diagnosed when $\mathrm{mPAP}>20 \mathrm{mmHg}$ is associated with abnormal PVR $\geqslant 3$ Wood units. With such a conservative approach, retrospective analysis of large registries from expert pulmonary vascular centres showed that the number of patients diagnosed with pre-capillary $\mathrm{PH}$ would increase by less than $10 \%$ with the revised haemodynamic definition (G. Simonneau, H-A. Ghofrani and R. Souza, personal communication). This number will have to be confirmed in prospective registries. Additionally, as stated by the task force members, a change in the haemodynamic definition of $\mathrm{PH}$ due to pulmonary vascular diseases does not imply treating these additional patients, but highlights the importance of further research, close monitoring and individualised management [5]. Last but not least, $\mathrm{mPAP}>20 \mathrm{mmHg}$ is a biomarker of worse outcomes in different settings, irrespective of the presence of a treatable pulmonary vascular disease, for example in the highly prevalent $\mathrm{PH}$ groups due to left heart diseases and/or chronic lung diseases. With all these considerations at hand, Simonneau et al. [5] had no reasonable choice other than to propose redefining $\mathrm{PH}$ and they are to be congratulated for making this long-awaited decision.

Conflict of interest: M.M. Hoeper reports personal fees for speaking/consultancy from Actelion, Bayer, GSK and MSD. M. Humbert reports personal fees for speaking/consultancy from Actelion, MSD and United Therapeutics, and grants and personal fees for speaking/consultancy from Bayer and GSK.

\section{References}

1 Hatano S, Strasser T. Primary pulmonary hypertension: Report on a WHO meeting, Geneva 15-17 October 1973. Geneva, World Health Organization, 1975.

2 Galie N, Torbicki A, Barst R, et al. Guidelines on diagnosis and treatment of pulmonary arterial hypertension. The Task Force on Diagnosis and Treatment of Pulmonary Arterial Hypertension of the European Society of Cardiology. Eur Heart J 2004; 25: 2243-2278.

3 Badesch DB, Champion HC, Sanchez MA, et al. Diagnosis and assessment of pulmonary arterial hypertension. J Am Coll Cardiol 2009; 54: Suppl. 1, S55-S66.

4 Galie N, Hoeper MM, Humbert M, et al. Guidelines for the diagnosis and treatment of pulmonary hypertension The Task Force for the Diagnosis and Treatment of Pulmonary Hypertension of the European Society of Cardiology (ESC) and the European Respiratory Society (ERS), endorsed by the International Society of Heart and Lung Transplantation (ISHLT). Eur Heart J 2009; 30: 2493-2537.

5 Simonneau G, Montani D, Celermajer DS, et al. Haemodynamic definitions and updated clinical classification of pulmonary hypertension. Eur Respir J 2019; 53: 1801913.

6 Gurtner HP. Haufung der primar vaskularen pulmonalen Hypertonie in der Schweiz 1967-1970. Schlusswort. [Accumulation of primary vascular pulmonary hypertension in Switzerland during 1967-1970. Concluding remarks]. Schweiz Med Wochenschr 1970; 100: 2158-2159.

7 Kovacs G, Berghold A, Scheidl S, et al. Pulmonary arterial pressure during rest and exercise in healthy subjects: a systematic review. Eur Respir J 2009; 34: 888-894

8 Hoeper MM, Bogaard HJ, Condliffe R, et al. Definitions and diagnosis of pulmonary hypertension. J Am Coll Cardiol 2013; 62: Suppl. 25, D42-D50.

9 Maron BA, Brittain EL, Choudhary G, et al. Redefining pulmonary hypertension. Lancet Respir Med 2018; 6: $168-170$.

10 Valerio CJ, Schreiber BE, Handler CE, et al. Borderline mean pulmonary artery pressure in patients with systemic sclerosis: transpulmonary gradient predicts risk of developing pulmonary hypertension. Arthritis Rheum 2013; 65: 1074-1084.

11 Kovacs G, Maier R, Aberer E, et al. Borderline pulmonary arterial pressure is associated with decreased exercise capacity in scleroderma. Am J Respir Crit Care Med 2009; 180: 881-886.

12 Bae S, Saggar R, Bolster MB, et al. Baseline characteristics and follow-up in patients with normal haemodynamics versus borderline mean pulmonary arterial pressure in systemic sclerosis: results from the PHAROS registry. Ann Rheum Dis 2012; 71: 1335-1342.

13 Stamm A, Saxer S, Lichtblau M, et al. Exercise pulmonary haemodynamics predict outcome in patients with systemic sclerosis. Eur Respir J 2016; 48: 1658-1667.

14 Hachulla E, Gressin V, Guillevin L, et al. Early detection of pulmonary arterial hypertension in systemic sclerosis: a French nationwide prospective multicenter study. Arthritis Rheum 2005; 52: 3792-3800. 
15 Humbert M, Yaici A, de Groote P, et al. Screening for pulmonary arterial hypertension in patients with systemic sclerosis: clinical characteristics at diagnosis and long-term survival. Arthritis Rheum 2011; 63: 3522-3530.

16 Coghlan JG, Denton CP, Grunig E, et al. Evidence-based detection of pulmonary arterial hypertension in systemic sclerosis: the DETECT study. Ann Rheum Dis 2014; 73: 1340-1349.

17 Montani D, Dorfmuller P, Girerd B, et al. Natural history over 8 years of pulmonary vascular disease in a patient carrying biallelic EIF2AK4 mutations. Am J Respir Crit Care Med 2018; 198: 537-541.

18 Girerd B, Montani D, Jais X, et al. Genetic counselling in a national referral centre for pulmonary hypertension. Eur Respir J 2016; 47: 541-552.

19 Kim NH, Delcroix M, Jais X, et al. Chronic thromboembolic pulmonary hypertension. Eur Respir J 2019; 53: 1801915 .

20 Taboada D, Pepke-Zaba J, Jenkins DP, et al. Outcome of pulmonary endarterectomy in symptomatic chronic thromboembolic disease. Eur Respir J 2014; 44: 1635-1645.

21 Guth S, Wiedenroth CB, Rieth A, et al. Exercise right heart catheterization before and after pulmonary endarterectomy in patients with chronic thromboembolic disease. Eur Respir J 2018; 52: 180458.

22 Hoeper MM, Humbert M, Souza R, et al. A global view of pulmonary hypertension. Lancet Respir Med 2016; 4: 306-322.

23 Hamada K, Nagai S, Tanaka S, et al. Significance of pulmonary arterial pressure and diffusion capacity of the lung as prognosticator in patients with idiopathic pulmonary fibrosis. Chest 2007; 131: 650-656.

24 Weitzenblum E, Hirth C, Ducolone A, et al. Prognostic value of pulmonary artery pressure in chronic obstructive pulmonary disease. Thorax 1981; 36: 752-758.

25 Douschan P, Kovacs G, Avian A, et al. Mild elevation of pulmonary arterial pressure as a predictor of mortality. Am J Respir Crit Care Med 2018; 197: 509-516.

26 Maron BA, Hess E, Maddox TM, et al. Association of borderline pulmonary hypertension with mortality and hospitalization in a large patient cohort: insights from the Veterans Affairs Clinical Assessment, Reporting, and Tracking Program. Circulation 2016; 133: 1240-1248.

27 Assad TR, Maron BA, Robbins IM, et al. Prognostic effect and longitudinal hemodynamic assessment of borderline pulmonary hypertension. JAMA Cardiol 2017; 2: 1361-1368.

28 Galie N, Humbert M, Vachiery JL, et al. 2015 ESC/ERS Guidelines for the diagnosis and treatment of pulmonary hypertension. Eur Respir J 2015; 46: 903-975.

29 Galie N, Humbert M, Vachiery JL, et al. 2015 ESC/ERS Guidelines for the diagnosis and treatment of pulmonary hypertension. Eur Heart J 2016; 37: 67-119.

30 Vachiery JL, Tedford RJ, Rosenkranz S, et al. Pulmonary hypertension due to left heart disease. Eur Respir J 2019; 53: 1801897.

31 Nathan SD, Barbera JA, Gaine SP, et al. Pulmonary hypertension in chronic lung disease and hypoxia. Eur Respir J 2019; 53: 1801914 